\title{
PROFIL HAMBATAN BELAJAR EPISTIMOLOGIS SISWA SMA PADA MATERI PERSAMAAN GAS IDEAL BERBASIS HASIL ANALISIS TES KEMAMPUAN RESPONDEN
}

\author{
Arif Rahmatullah $^{\text {a)}}$, Heni Rusnayatib), A.F.C. Wijaya ${ }^{\text {c) }}$ \\ Departemen Pendidikan Fisika, Fakultas Pendidikan Matematika dan Ilmu Pengetahuan Alam, Universitas \\ Pendidikan Indonesia, Jl. Dr. Setiabudi No.229, Bandung 40154 \\ Email: a) arif.rahmatullah95@student.upi.edu,b)heni@upi.edu, c)agus.fany@gmail.com
}

\begin{abstract}
Abstrak
Hasil studi pendahuluan yang dilakukan peneliti melalui tes dan angket diperoleh 51,5\% siswa mengalami hambatan belajar epistimologis pada materi persamaan gas ideal. Hambatan belajar epistimologis yang dimaksud adalah hambatan yang dialami oleh siswa karena keterbatasan pada konteks tertentu. Penelitian ini bertujuan untuk mengidentifikasi profil hambatan belajar epistimologis siswa pada materi persamaaan gas ideal berdasarkan hasil analisis tes kemampuan responden. Metode penelitian yang digunakan adalah metode deskriptif kualitatif dengan analisis pendekatan historis melalui tes kemampuan responden berupa empat soal uraian yang mencakup konsep esensial persamaan gas ideal, soal uraian tersebut diberikan kepada siswa yang telah mempelajari materi persamaan gas ideal di salah satu SMA Negeri Kota Bandung. Hasil penelitian menunjukkan bahwa siswa mengalami hambatan belajar epistimologis pada materi persamaan gas ideal, diantaranya dalam mengidentifikasi soal termasuk proses isotermik, menginterpretasikan grafik pada proses isobarik, menentukan banyaknya partikel yang keluar pada tangki bocor pada konsep persamaan gas ideal, serta menerapkan konsep rapat massa pada persamaan gas ideal dalam kasus balon udara. Dengan demikian dapat disimpulkan bahwa masih terdapat hambatan belajar epistimologis pada materi persamaan gas ideal, sehingga ada upaya untuk meminimalisir hambatan belajar epistimologis pada materi persamaan gas ideal.
\end{abstract}

Kata-kata kunci: Hambatan Belajar, Tes Kemampuan Responden, Persamaan Gas Ideal.

\begin{abstract}
Results of a preliminary study conducted by researchers through test and questionnaire obtained 51.5\% of students experienced epistemological learning obstacles on the ideal gas equation. Epistemological learning obstacles occur due to one's limit only to a certain concept. This study aimed to identify the student's epistemological learning obstacles profile ideal gas equation material based on the analysis tests the ability of respondents. The method used in this study is qualitative descriptive, combined with the historical approach analysis through the respondent's ability test, in the form of four essays covering essential concept of the ideal gas equation, which given to the students in one High School in Bandung, who had learned about ideal gas equation.The results showed that students experiencing epistemological learning obstacles on the material ideal gas equation, including in identifying problems including process isotermik, interpreting graphs on isobaric process, determine the number of particles that come out on the tank leaked on the concept of equality ideal gas, and apply the concept of mass meetings in
\end{abstract}


equation ideal gas in the case of a hot air balloon. It can be concluded that there are still epistemological learning obstacles on the material ideal gas equation.

Keywords: Learning Obstacles, Respondent’s Ability Test, Ideal Gas Equation.

\section{PENDAHULUAN}

Menurut UU Nomor 20 tahun 2003, Pembelajaran adalah proses interaksi peserta didik dengan pendidik dan sumber belajar pada suatu lingkungan belajar, dari pernyataan diatas terdapat tiga komponen yang sangat penting dalam proses pembelajaran, diantaranya: Pendidik, Peserta didik, dan Sumber belajar. Agar menghasilkan pembelajaran yang baik, maka kualitas dari setiap masing masing komponen tersebut harus memiliki kualitas yang baik pula. Bukan hal yang mustahil apabila interaksi antara ketiga komponen terbentuk dengan baik, maka tujuan pendidikan nasional dapat tercapai.

Adapun tujuan pendidikan nasional adalah berkembangnya potensi peserta didik agar menjadi manusia yang beriman dan bertakwa kepada Tuhan Yang Maha Esa, berakhlak mulia, sehat, berilmu, cakap, kreatif, mandiri, dan menjadi warga negara yang demokratis serta bertanggung jawab. Belajar fisika pada dasarnya adalah belajar mengenai pemahaman terhadap konsep, teori atau hukum-hukum fisika. Namun pada prakteknya dilapangan banyak siswa mengalami hambatan dalam memahami konsep, teori atau hukum-hukum fisika.

Brosseau (2002) membagi sumber hambatan belajar menjadi tiga, yaitu :

- Hambatan Didaktis, adalah hambatan belajar yang muncul akibat dari kekeliruan proses pembelajaran, biasanya dapat berupa penyampaian materi yang kurang tepat oleh pendidik ke peserta didik. Hambatan ini biasanya sering muncul dalam proses pembelajaran dengan tanpa disadari oleh pendidik.

- Hambatan Ontogeni, adalah keterbatasan (neurofisiologis) siswa pada saat perkembangannya. Siswa yang mengalami hambatan belajar ini, salah satu penyebabnya karena siswa tidak mengalami pola perkembangan kognitif seperti seharusnya.

- Hambatan Epistimologis, adalah hambatan belajar yang muncul akibat keterbatasan konteks peserta didik dalam memahami suatu konsep. Sehingga ketika disajikan suatu permasalahan dengan konsep yang sama namun konteks yang berbeda peserta didik tidak dapat menyelesaikannya.

Hambatan belajar yang akan dikaji dalam makalah ini adalah hambatan epistimologis, hambatan belajar epistimologis siswa dapat dilihat dari hasil studi pendahuluan yang telah dilakukan oleh peneliti pada salah satu SMA di Kota Bandung, dengan memberikan angket dan tes diketahui sebanyak 51,5\% siswa mengalami hambatan belajar epistimologis pada materi persamaan gas ideal. Berdasarkan hasil tes yang telah diberikan sebanyak 63,6 \% siswa tidak memahami makna dari isobarik, isotermik dan isohorik dan sebanyak $72,7 \%$ siswa tidak dapat menentukan tekanan gas dari persamaan gas ideal.

Berdasarkan studi pendahuluan tersebut peneliti bertujuan untuk mengidentifikasi profil hambatan belajar epistimologis siswa kelas XII SMA pada materi persamaaan gas ideal berdasarkan hasil analisis tes kemampuan responden (TKR).

\section{METODE PENELITIAN}

Penelitian ini menggunakan metode deskriptif kualitatif dengan analisis pendekatan historis yang merupakan ungkapan dari buku Theory of Didactical Situation, Brosseau (2002) dengan menggunakan Tes Kemampuan Responden (TKR) berupa tes uraian yang terdiri atas tes tertulis sebanyak 4 (empat) soal yang mencakup konsep esesial dari materi persamaan gas ideal. Soal berbentuk essay ini bertujuan supaya tergambar pola pikir mereka dalam menjawab soal serta jawaban yang dipilih merupakan hasil pemikiran terlebih dahulu. TKR diberikan pada siswa yang telah mempelajari materi persamaan gas ideal. Sebelum dilaksanakan TKR, instrumen dilakukan 
validasi terlebih dahulu melalui judgement guru dan dosen pembimbing. Subjek penelitian ini yaitu siswa kelas XII di salah satu SMA Negeri di Kota Bandung yang berjumlah 35 orang.

\section{HASIL DAN PEMBAHASAN}

Berdasarkan hasil penelitian yang telah dilakukan dilakukan terdapat hambatan epistimologis siswa pada konsep - konsep esensial materi persamaan gas ideal melalui Tes Kemampuan Responden (TKR) dengan uraian sebagai berikut:

\section{Hukum Boyle (Isotermik)}

Berikut merupakan tabel hambatan belajar epistimologis yang muncul pada konsep hukum isotermik :

TABEL 1. Hambatan Belajar Peserta Didik Pada Konsep Isotermik.

\begin{tabular}{clc}
\hline Coding & \multicolumn{1}{c}{ Hambatan } & Persentase \\
& & TKR Awal \\
\hline 1 & $\begin{array}{l}\text { Tidak dapat mengidentifikasi besaran fisis } \\
\text { dengan tepat pada proses isotermik }\end{array}$ & $60 \%$ \\
\hline 2 & Tidak dapat menentukan proses isotermik & $100 \%$ \\
\hline 3 & $\begin{array}{l}\text { Tidak dapat menentukan persamaan pada } \\
\text { keadaan isotermik }\end{array}$ & $65,71 \%$ \\
\hline 4 & $\begin{array}{l}\text { Tidak dapat mengubah bentuk persamaan } \\
\text { menjadi grafik isotermik }\end{array}$ & $82 \%$ \\
\hline
\end{tabular}

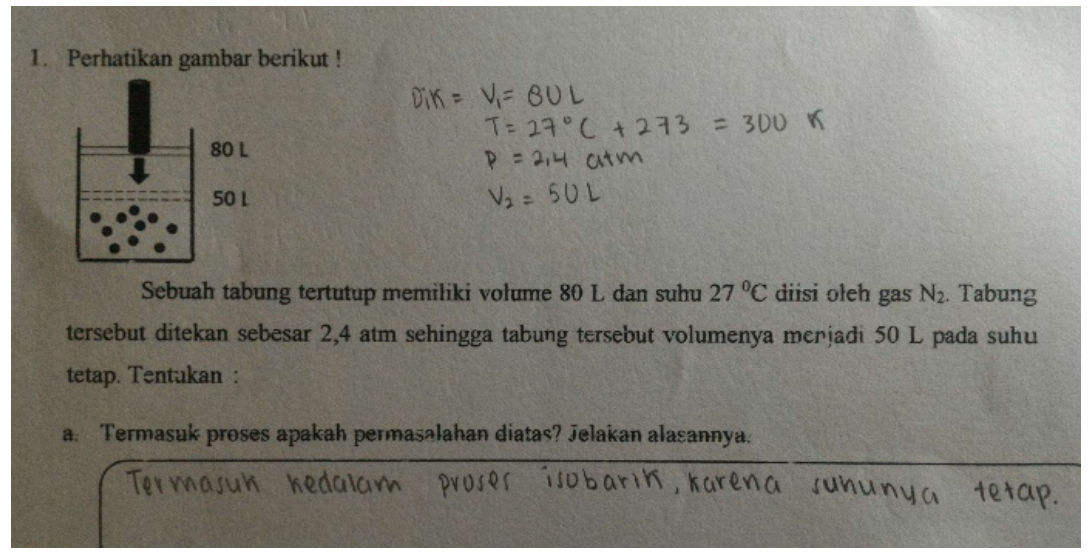

GAMBAR 1. Jawaban Siswa pada Soal Nomor 1a untuk Coding 2

Dari gambar diatas siswa mengalami hambatan pada coding 2 yaitu siswa menjawab bahwa proses yang terjadi adalah proses isobarik karena suhunya tetap, Seharusnya proses yang terjadi adalah proses isotermik karena pada proses isotermik suhu dijaga tetap. Hal tersebut disebabkan karena siswa masih belum memahami makna dari istilah proses isotermik, isobarik maupun isohorik. 


\section{Hukum Charles (Isobarik)}

Berikut merupakan tabel hambatan belajar epistimologis yang muncul pada konsep hukum isobarik:

TABEL 2. Hambatan Belajar Peserta Didik pada Konsep Isobarik.

\begin{tabular}{clc}
\hline Coding & \multicolumn{1}{c}{ Hambatan } & Persentase \\
\hline 1 & $\begin{array}{l}\text { Tidak dapat mengurutkan tekanan terbesar ke } \\
\text { tekanan terkecil dari sebuah grafik isobarik }\end{array}$ & TKR Awal \\
\hline 2 & $\begin{array}{l}\text { Tidak memahami makna dari gradien (kemiringan } \\
\text { garis), pada grafik isobarik }\end{array}$ & $100 \%$ \\
\hline
\end{tabular}

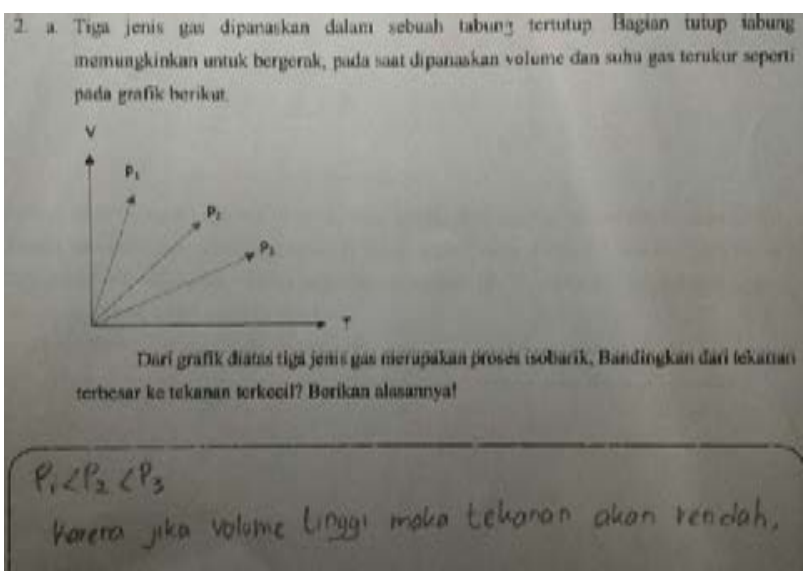

GAMBAR 2. Jawaban Siswa pada Soal Nomor 2a untuk Coding 2

Dari gambar diatas siswa mengalami hambatan pada coding B2 yaitu siswa sudah dapat mengurutkan dari tekanan terbesar ke tekanan terkecil, namun saja alasan yang dikemukakan oleh siswa masih salah. Hal tersebut disebabkan karena siswa belum memahami makna dari kemiringan garis grafik isobarik.

\section{Hukum Gay-Lusac (Isohorik)}

Berikut merupakan tabel hambatan belajar epistimologis yang muncul pada konsep hukum isohorik :

TABEL 3. Hambatan Belajar Peserta Didik pada Konsep Isohorik.

\begin{tabular}{clc}
\hline Coding & Hambatan & Persentase \\
\hline 1 & $\begin{array}{l}\text { Tidak dapat mengurutkan tekanan terbesar ke } \\
\text { tekanan terkecil dari sebuah beberapa kondisi } \\
\text { isohorik }\end{array}$ & $100 \%$ \\
\hline
\end{tabular}




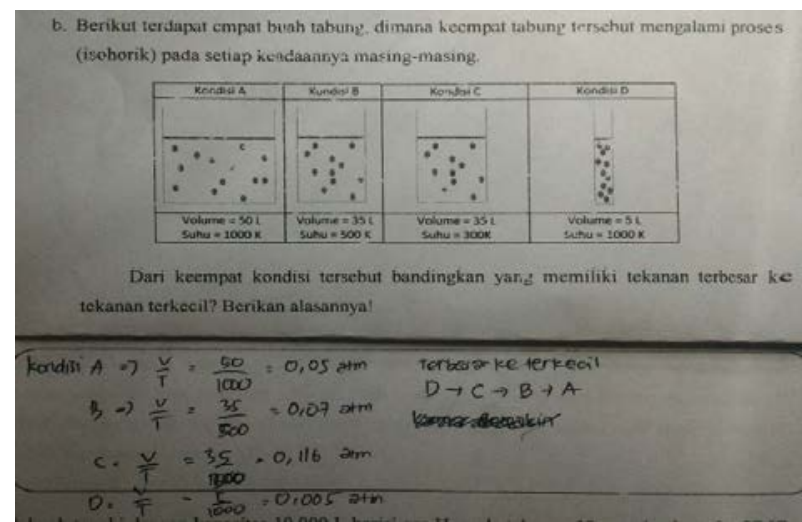

GAMBAR 3. Jawaban Siswa pada Soal Nomor 2b untuk Coding 1

Dari gambar diatas siswa mengalami hambatan pada coding C1 yaitu siswa tidak dapat mengurutkan dari tekanan terbesar ke tekanan terkecil, hal tersebut dikarenakan siswa tidak memahami persamaan isohorik.

\section{PERSAMAAN GAS IDEAL} ideal:

Berikut merupakan tabel hambatan belajar epistimologis yang muncul pada konsep persamaan gas

TABEL 4. Hambatan Belajar Peserta Didik pada Konsep Persamaan Gas Ideal.

\begin{tabular}{clc} 
Coding & Hambatan & $\begin{array}{c}\text { Persentase } \\
\text { TKR Awal }\end{array}$ \\
\hline 1 & $\begin{array}{l}\text { Tidak dapat mengidentifikasi besaran fisis dengan tepat pada } \\
\text { persamaan gas ideal }\end{array}$ & $48,57 \%$ \\
2 & Tidak dapat menentukan persamaan gas ideal & $80 \%$ \\
3 & Tidak dapat menentukan massa gas dari persamaan gas ideal & $100 \%$ \\
4 & $\begin{array}{l}\text { Tidak dapat menentukan banyak partikel dari persamaan gas } \\
\text { ideal }\end{array}$ & $100 \%$ \\
5 & $\begin{array}{l}\text { Tidak dapat menentukan rapat massa berkaitan dengan } \\
\text { persamaan gas ideal }\end{array}$ & $100 \%$ \\
6 & \begin{tabular}{l} 
Tidak dapat menjelaskan prinsip kerja dari balon udara \\
\hline
\end{tabular} & $100 \%$ \\
\hline
\end{tabular}

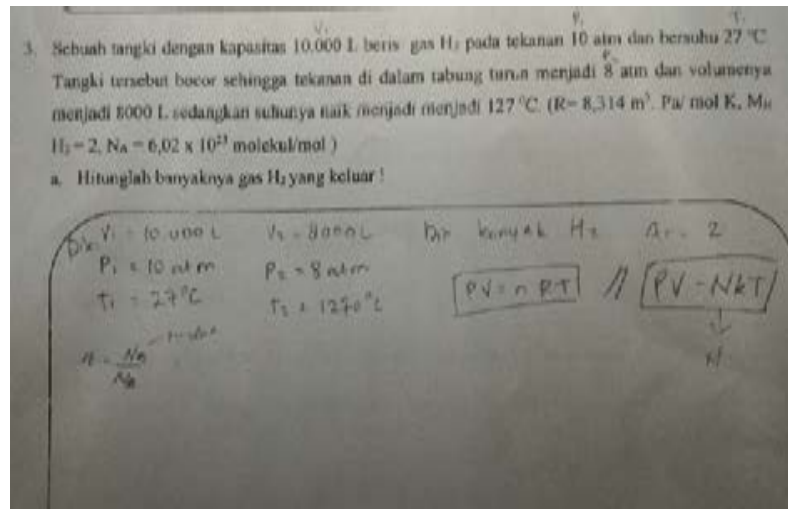

GAMBAR 4. Jawaban Siswa pada Soal Nomor 3a untuk Coding 3 
Dari gambar diatas siswa mengalami hambatan pada coding D3 yaitu siswa tidak dapat menentukan massa gas dari soal diatas, Hal tersebut dikarenakan siswa tidak memahami apa yang ditanyakan dari soal dan tidak dapat menggunakan persamaan gas ideal untuk mencari massa gas.

\section{SIMPULAN}

Berdasarkan data dan hasil pembahasan diperoleh kesimpulan bahwa masih terdapat hambatan belajar epistimologis pada materi persamaan gas ideal, diantaranya:

1. Tidak dapat menentukan proses isotermik;

2. Tidak memahami makna dari gradien (kemiringan garis), pada grafik isobarik;

3. Tidak dapat mengurutkan tekanan terbesar ke tekanan terkecil dari sebuah beberapa kondisi isohorik; serta

4. Tidak dapat menentukan massa gas dari persamaan gas ideal.

Dengan demikian perlu adanya suatu upaya untuk meminimalisir hambatan belajar epistimologis pada materi persamaan gas ideal.

\section{UCAPAN TERIMAKASIH}

1. Ibu Heny Rusnayati, M.Si., selaku pembimbing akademik dan pembimbing I, serta Bapak Agus Fany Chandra Wijaya, M.Pd., selaku pembimbing II yang selalu membimbing dan mendorong penulis untuk makalah ini.

2. Seluruh Pembimbing dan Tim Dosen dalam payung penelitian DDR yang telah memberikan kesempatan, dukungan dan perhatiannya kepada penulis.

\section{REFERENSI}

[1] Pemerintah Republik Indonesia, Undang-Undang Republik Indonesia No. 20 Tahun 2003 tentang Sistem Pendidikan Nasional, Jakarta, 2003.

[2] G. Brosseau, Theory of Didactical Simulations in Mathematics, New York: Kluwer Academic Publisher, 2002.

[3] N. Fauzan, "Desain didaktis konsep usaha kelas XI SMA berdasarkan analisis kesulitan belajar siswa”. Skripsi: Universitas Pendidikan Indonesia, 2015.

[4] F. D. M. Wina, "Desain didaktis materi penjumlahan vector berdasarkan hambatan belajar pada siswa SMA kelas X”, Skripsi: Universitas Pendidikan Indonesia, 2016.

[5] Sugiyono, Metode Penelitian Pendekatan Kuantitatif, Kualitatif, dan $R$ \& D, Bandung: Alfabeta, 2014.

[6] D. Suryadi, Didactical Design Research (DDR) dalam Pengembangan Pembelajaran Matematika, UNNES: Seminar Pendidikan Matematika, Available: http://didisuryadi.staf.upi.edu/files/2011/06/DIDACTICAL-DESIGN-RESEARCH-DDR.pdf, 2013 